\title{
Pattern of lethal trauma among swimmers colliding with a personal watercraft
}

\author{
Bledar Xhemali ${ }^{1}$, Gentian Vyshka ${ }^{2}$, Admir Sinamati $^{1}$, Elmas Shaqiri ${ }^{1}$ \\ ${ }^{1}$ Department of Forensic Pathology, Institute of Legal Medicine, Ministry of Justice in Tirana, Albania \\ ${ }^{2}$ Biomedical and Experimental Department, Faculty of Medicine, University of Medicine in Tirana, Albania
}

\begin{abstract}
Personal watercrafts (otherwise known as Jet Skis or wave runners) possess powerful propelling engines that enable them to reach high velocities. In overcrowded sea shores, especially due to a diversity of human errors (inexperience, underage operator, alcohol-related errors and lack of training), these vessels might cause severe damage to the operator himself, to swimmers in the whereabouts but to the environment as well. We present three fatal victims that were struck and overrun by personal watercrafts used for recreational purposes. One of them had a deep skull trauma resulting from being hit by the hull of the vessel. The other two cases had an impressive and particular pattern of tissue trauma, with deep parallel cutting wounds due to the contact with the propeller helix. All cases were treated as accidental drowning, because even when rescue operations were immediate, the loss of conscience following the severe blunt trauma inside the water left few chances, if any, to survival.
\end{abstract}

(Int Marit Health 2017; 68, 4: 187-189)

Key words: personal watercraft, Jet Ski, drowning, trauma, accidental drowning

\section{INTRODUCTION}

Personal watercrafts (PWCs) for recreational purposes have seen an explosive growth in usage during the last few years in Albanian sea waters and beaches. In the hands of unprofessional users, with scarce training, if any at all, and with defective regulations as by the actual date, swimmers have been sometimes victims of the hazardous use of PWC in Albanian coastal regions.

Since their inception, PWC have seen an increasing use in the seashores and lakes all over the world, but injuries related to their use have become a public health issue, mainly because of lack of expertise from users. Powerful as they are, they are often called by other terms, such as Jet Skis or wave runners, that point out their velocity. Due to their propelling mechanism of work and potent engines, they have become part of variegated water sport activities.

Several authoritative sources have collected their own epidemiological data and pointed out mechanisms of injuries in boating-related death; water skiing (and related activities), PWC riding, boating (including fishing from boats), sailing, canoeing and kayaking have all been included [1].
Most of the reported accidents have been related to injuries or death of the user himself [2]. In fact, accidental fatalities of swimmers overrun or directly hit by PWCs are still a rarity, with no reason to think that this might be an underestimation of the events [3]. The collision with another PWC or Jet Ski, boat or fixed object is the principal mechanism of operator injury, but fall from the vessel should be considered as well, and some authors do even suggest the probability of $\mathrm{CO}$ intoxication of operators, due to the high level of pollution that is generated by the propulsion engines $[4,5]$. Here again, when reporting injuries such as multiple fractures, with head and neck region being principally and more seriously hit, reported cases are mainly of passengers; some of them suffer even from pelvic or abdominal injuries during the fall from the vessel. Another source suggest the chest injury to be the most common type, but once more we are talking about operators or passengers' injuries [6].

\section{CASE SERIES}

Albanian seashores have witnessed an increased use of PWCs during the last five-six years, but to date no effective 


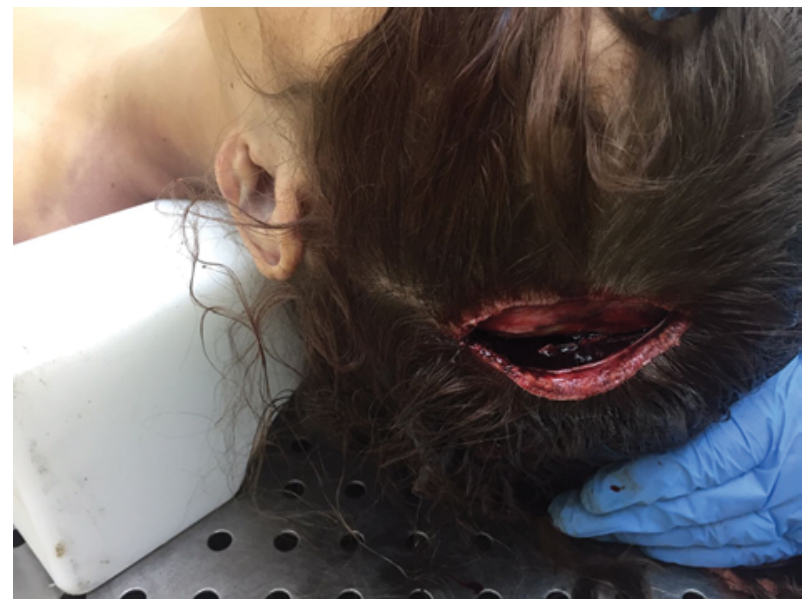

Figure 1. The head of the first victim, a young lady who was struck by the hull of a personal watercraft while swimming. The mechanism of death was drowning; apparently she lost conscience immediately upon collision. She was taken ashore only after approx. 10 minutes and pronounced dead from the first-aid responders

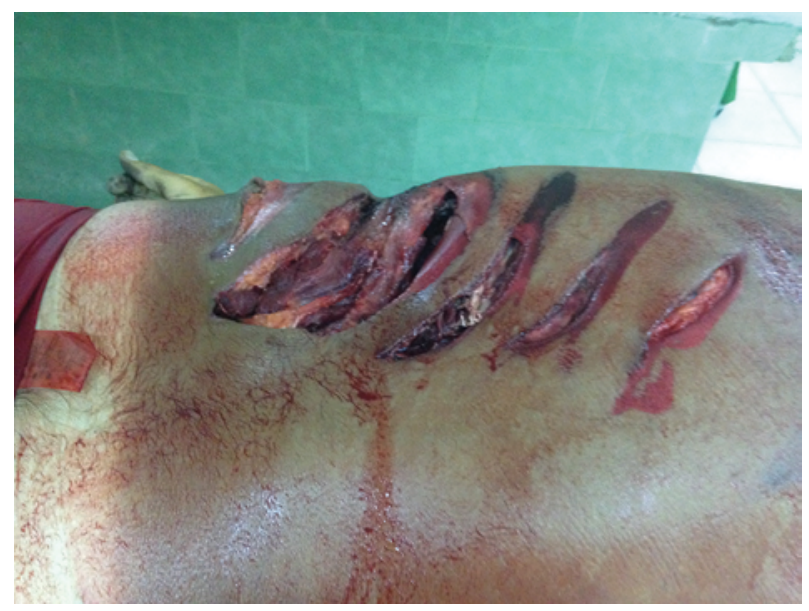

Figure 2. The fatal victim, a middle-aged male, was apparently struck by the helix of a large boat propeller. The collision was massive and blunt multiple traumas to the dorsum of the victim have caused profuse haemorrhage leading to a haemorrhagic shock, apart from the loss of conscience and drowning. Some tissue changes were also due to the fact that the corpse was recovered from the water with a large delay of time (the evening of the accident), because the vehicle that caused the collision left the scene unnoticed

training is offered to users, that frequently are minors in age, drive under alcohol influence or simply hire once in a while a vehicle.

We have had three declared fatalities in the last two years (two in the summer of 2016 and one fatality in the summer of 2017); the first fatality was a male, whereas the two other were females. Images below show the three parts

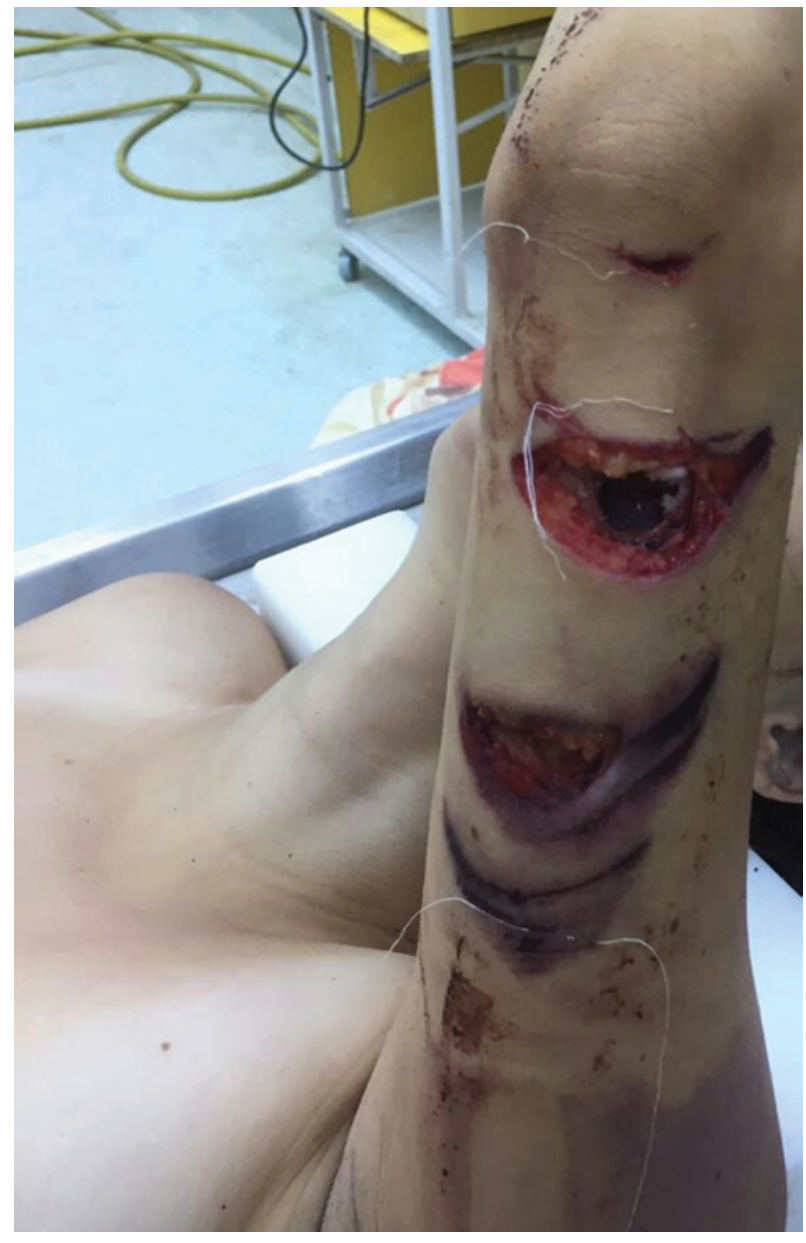

Figure 3. Third victim - a female adolescent whose left arm collided with the helix of a personal watercraft's propeller. Note the presence of almost parallel, although not identical in their severity, deep wounds with tissue laceration. The young victim lost conscience immediately and drowned; rescue operations were rapid but ineffective

of respective corpses who were all overrun by a recreational PWC; all these events occurred in the sea waters (Figs. 1-3).

As we note from the images of the three casualties generated from improper use of PWCs, traumas and collisions with these vehicles are extremely severe, and with a high potential of lethality. The hit region of the body (head or trunk) in the first two cases, especially the depth of tissue injuries in the second case (apparently colliding with a large boat), will leave no chance to survival. The mechanism of death of the third victim was accidental drowning due to loss of conscience following the trauma of the left arm.

\section{DISCUSSION}

Personal watercraft collision fatalities are not a common occurrence, with authors reporting mostly damage and injuries suffered from users themselves. Unfortunately, swimmers might be involved, and our cases were fatal due 
to diversity of reasons. Head, chest and limbs might suffer severe blunt trauma with profuse bleeding, but loss of conscience in the particular water environment will leave few chances of survival due to accidental drowning.

Personal watercrafts have been imputed for a diversity of damages, not only to humans. In fact these vehicles have powerful engines, producing high level of noise deleterious to aquatic species, apart from polluting severely waters and space [7]. The majority of sources when reporting accidents in fact are dealing with PWC operators, who might get hurt during falling from the vehicle, or even from the pressure of the water jet; there are no overall figures with regard to fatalities, and operators might survive in spite of different body injuries [8].

The reported number of cases involving swimmers colliding with recreational boating vessels has constantly increased. Accidents have been as well connected with alcohol abuse from riders; authors denominate differently these accidents, such as 'unintentional drowning', 'recreational boating fatality', 'accidental drowning' and so on [9]. The severity of blunt trauma is generally overshadowed by the drowning due to loss of conscience in the water. In fact, we have reported cases of survival following severe cranial trauma, but not in the setting of an aquatic environment [10].

Inexperience, lack of training, underage operating and alcohol abuse is not an exhaustive list of factors that might endanger swimmers of colliding with PWCs. Even swimmers themselves might show hazardous behaviours, such as swimming outside allowed areas, when appropriate signs are available and visible, mainly in the form of beach flags [11].

\section{CONCLUSIONS}

It seems that when discussing about Albanian beaches and seashore, a stronger control is needed, combined with updated, applicable and strict regulations with regard to possessing, riding or hiring boats for recreational usage. The recent and unprecedented presence of personal watercrafts has been accompanied by cases when careless swimmers have been overrun by PWCs, with deep traumas at diverse parts of the body and accidental drowning due to immediate loss of conscience.

\section{REFERENCES}

1. Ashby K, Cassel E. Boating-related sports and recreational injury, Victoria July 2000 to June 2002. Victorian Injury Surveillance \& Applied Research System (VISAR). Hazard. 2004; 56: 1-14.

2. Gill RS, Whitlock K. Epidemiology of Personal Watercraft Injuries. J Trauma Treatment. 2012; 1: 112, doi: 10.4172/21671222.1000112.

3. Rubin LE, Stein PB, DiScala C, et al. Pediatric trauma caused by personal watercraft: a ten-year retrospective. J Pediatr Surg. 2003; 38(10): 1525-1529, doi: 10.1016/s0022-3468(03)00507-4, indexed in Pubmed: 14577080.

4. Haan JM, Kramer ME, Scalea TM. Pattern of injury from personal watercraft. Am Surg. 2002; 68(7): 624-627, indexed in Pubmed: 12132746 .

5. McCammon JB, Jumbelic MI, Baron RL. Comments on watercraft-related drownings. Public Health Rep. 2004; 119(2): 112-113, indexed in Pubmed:15192896.

6. Al-Thani H, El-Menyar A, Mekkodathil A, et al. Types, Patterns and Outcomes of Personal Watercraft-Related Trauma. Ann Med Health Sci Res. 2017; 7: 39-43.

7. Bell W, Yassi A, Cole DC. On PMWs and two-stroke engines. Can Fam Physician. 1998; 44: 1775-7, 1787, indexed in Pubmed: 9789655.

8. Sidon E, Burg A, Ohana N, et al. Fracture of vertebra D12 in jet-ski accidents. Isr Med Assoc J. 2011; 13(8): 510-511, indexed in Pubmed: 21910380.

9. Driscoll TR, Harrison JA, Steenkamp M. Review of the role of alcohol in drowning associated with recreational aquatic activity. Inj Prev. 2004; 10(2): 107-113, doi: 10.1136/ip.2003.004390, indexed in Pubmed: 15066977.

10. Vyshka G, Troshani B, Bozaxhiu D, et al. Rotational head trauma with callosal contusion and $\mathrm{C} 6$ fracture: a high-speed motorcycle accident. Ulus Travma Acil Cerrahi Derg. 2013; 19(1): 77-79, doi: 10.5505/tjtes.2013.40374, indexed in Pubmed: 23588986.

11. Sherker S, Williamson A, Hatfield J, et al. Beachgoers' beliefs and behaviours in relation to beach flags and rip currents. Accid Anal Prev. 2010; 42(6): 1785-1804, doi: 10.1016/j.aap.2010.04.020, indexed in Pubmed: 20728630. 